\title{
Load Frequency Control of Multi Source Multi-Area Nonlinear Power System with DE-PSO Optimized Fuzzy PID Controller in Coordination with SSSC and RFB
}

\author{
Deepak Kumar Lal ${ }^{1}$, Ajit Kumar Barisal ${ }^{2}$ and Manish Tripathy ${ }^{3}$ \\ ${ }^{1,2,3}$ Department of Electrical Engineering, Veer Surendra Sai University of \\ Technology, Burla, Odisha, India

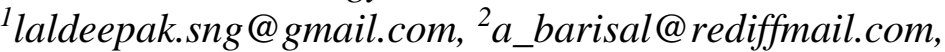 \\ ${ }^{3}$ manish_tripathy@yahoo.co.in
}

\begin{abstract}
This paper presents dynamic performance analysis of multi source multi area power system using Fuzzy PID controller optimized by hybrid Differential Evolution (DE) and Particle Swarm Optimization (PSO) technique. The proposed controller stabilizes the frequency deviations of both areas considering governor dead band (GDB), reheat turbine and generation rate constraint (GRC) with Redox Flow Battery (RFB) and Static Synchronous Series Compensator (SSSC). The dynamic performances of the system have been improved when compared with genetic algorithm tuned Integral controller and output feedback optimal controller for the identical system. Investigations affirm that Fuzzy PID controller gives much better response than I, PI and PID controllers. The proposed control scheme is more robust towards different loadings, system parameters change and random load perturbations.
\end{abstract}

Keywords: Generation rate constraint, fuzzy logic controller, differential Evolution \& particle swarm optimization, redox flow battery, static synchronous series compensator

\section{Introduction}

An electric power system consists of diverse sources of power generations such as Hydro, Thermal, Gas, Diesel, Nuclear, Solar, Wind etc. and many control areas connected by tie lines. Nuclear units owing to their high efficiency are usually kept at base load close to their maximum output with no participation in automatic load frequency control (ALFC). Gas power generation is ideal for meeting varying load demand hence improving the reliability and security of power system. In a multi area power system the generators and loads are coordinated with each other through the tie lines among the areas. For stable operation of the system the generation of power must match with the total power demand plus losses [1]. But the total power demand by the loads varies continuously throughout the days causing frequency deviations in each area and tie line power flow deviation. Hence, load frequency control (LFC) plays a vital role in modern power system. The LFC is to maintain the system frequency at a specified nominal value and to preserve the tieline power interchanges between different control areas at their scheduled values [1]. Various LFC aspects, strategies and control methodologies have been discussed in [2]. The design and analysis of load frequency controller for two area hydro-thermal-gas has been presented in [3]. The performance analysis of several classical PID controllers for multi area power system is presented by Saikia et al., [4] and the proposed IntegralDouble Derivative controller (IDD) provides much better response than other classical PID controller structures such as Integral (I), Proportional-Integral (PI), Integral-

Received (October 6, 2017), Review Result (December 6, 2017), Accepted (December 15, 2017) 
Derivative (ID) and Proportional-Integral-Derivative (PID) controllers. The two-degreeof-freedom PID (2-DOF-PID) controller for three area power system optimized by firefly algorithm (FA) is reported in [5] and proved better than other classical controllers. The study of two areas and multi source power system catered by hydro, thermal and gas power generations with an optimal output feedback controller [6] is investigated and suggested that it is better than full state feedback controller. The artificial intelligent techniques based PID controllers have been proposed for the similar power system [7-8]. The results show that the frequency stabilization of PID controller tuned using intelligent techniques perform better than an optimal output feedback controller.

The frequency fluctuations are not corrected suddenly because of slow governor response, even in the case of small load perturbation, change in operating point and optimized gain for the supplementary controllers. Hence, the frequency and tie line power deviations persist for a long duration and not acceptable practically. To overcome this problem, energy storage devices such as Super Conducting Magnetic Energy Storage (SMES), Capacitive Energy Storage (CES) and Redox Flow Battery (RFB) etc. play a vital role to ensure improved system performance and provide an alternative option to damp out oscillations effectively in power system. Banerjee et al., [9] investigated the effectiveness of small-sized superconducting and normal loss types Magnetic Energy Storage (MES) units for load frequency control and suggested the importance of best utilization of small energy storage capacity of such units to improve the dynamics performance of large power system. Both active as well as reactive powers can be varied simultaneously by SMES unit to improve the dynamic and transient responses of generators in power areas. The energy storage devices can be charged during the off-peak periods and the stored energy is used during the peak periods. It provides storage capacity in addition to kinetic energy of the generator rotor, which can share the sudden changes in power requirement. Therefore, many researchers have reported various LFC schemes incorporating SMES, CES and RFB [10-12] for improving load frequency performance.

Due to rapid growth of power electronics components, recent advancement in semiconductor technology, market expansion and the declined cost have drawn the attention of power engineers towards Flexible AC Transmission System (FACTS) devices. Recently, many works have been reported towards development of FACTS devices to meet the present day's high quality requirements. It has the potential to enhance power system stability by controlling the power flow in an interconnected power system [13]. Literature review reveals that FACTS devices with coordinated operation of energy storage devices give excellent dynamical performance of the system. To damp out the power system frequency oscillations effectively, Abraham et al. applied a Thyristor Controlled Phase Shifters (TCPS) in two area hydro-thermal power system [14] and multisource power system by Parmar et al., [15]. Thyristor Controlled Series Capacitor (TCSC) an economical and high performance series compensator belongs to FACTS family is presented for LFC to stabilize the power oscillations and improves the dynamic stability [16]. The improved performance of the system is investigated with application of Static Synchronous Series Compensator (SSSC) for LFC study [17-18]. A small signal stability analysis is performed for a two areas interconnected power system using an integral controller optimized by GA incorporated with FACTS and RFB [18]. The improved dynamic performance of a two area multisource power systems is reported with the application of Unified Power Flow Controller (UPFC) in coordination of SMES units [19]. The LFC incorporating with SMES-TCPS and SSSC for a two-area hydro-hydro system is investigated and their performances are compared by claiming SMES better than others [20]. A comparative performances evaluation of different FACTS devices with energy storage devices have been conducted in [21]. From comparative results, IPFC is proven to be a promising alternative for frequency and tie-line power stabilization.

It is revealed from the literature review that the performance of the overall system depends both on the controller structure and optimization technique used for tuning of 
controller parameters. In the past several control methodologies such as classical control, optimal control, adaptive control, fuzzy logic control (FLC) and neural network control have been proposed for LFC of power system. Several literatures prove the success of fuzzy logic controllers for LFC of non-linear power system. A self tuning fuzzy PID type controller for LFC of two area interconnected power system is proposed by Yesil et al., [22]. Various heuristic optimization techniques have been proposed for tuning of PID gains used in fuzzy logic based LFC problem [21-23]. A hybrid of Differential Evolution (DE) algorithm and Particle Swarm Optimization (PSO), (DE-PSO) technique provides better performance than DE and PSO is reported by [23] for LFC of two area non-reheat thermal power system.

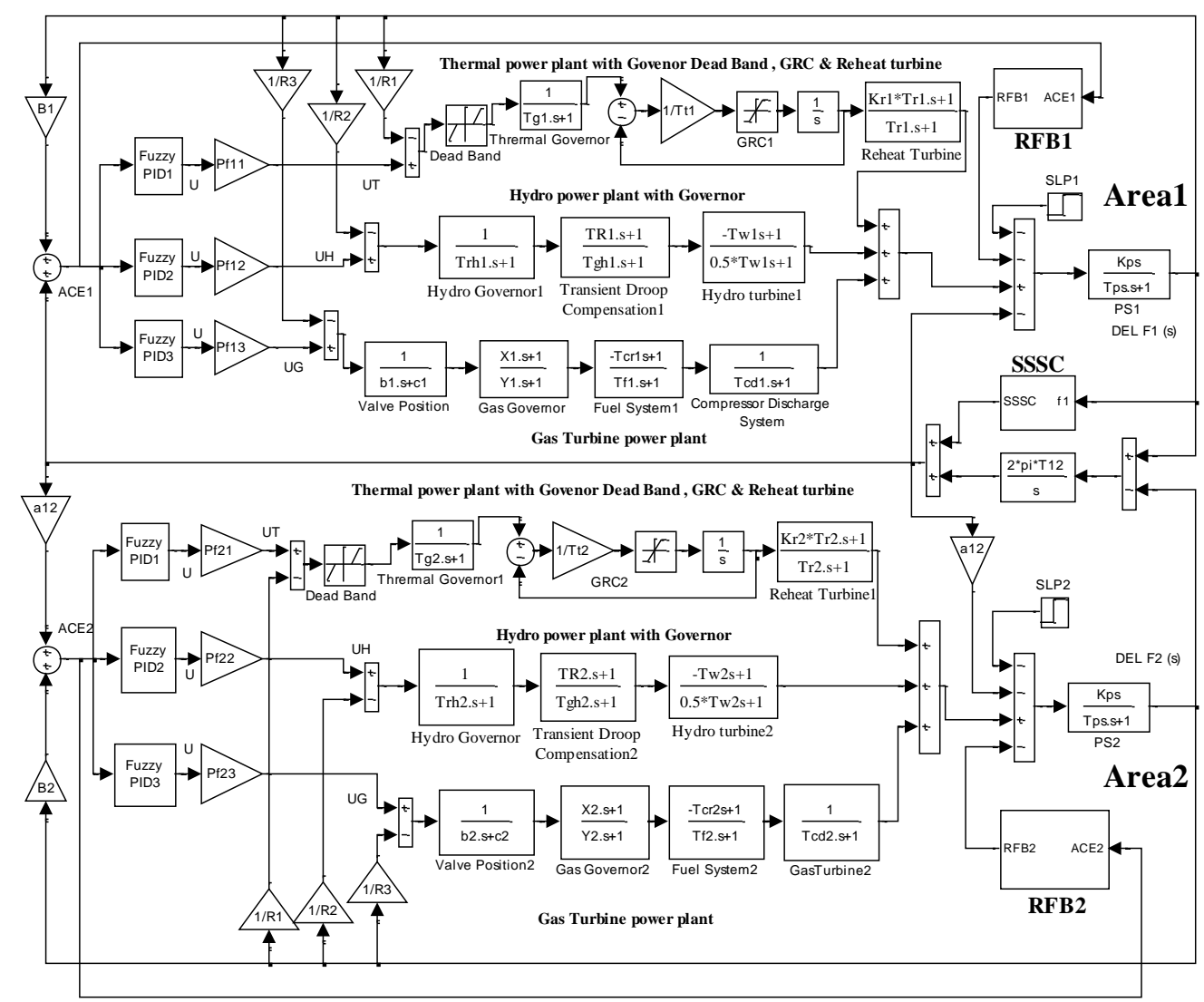

Figure 1. Transfer Function Model of Multi-Source Multi-Area Power System

The DE and PSO algorithm are population based stochastic algorithms for global optimization introduced by Storn Rainer and Kenneth Price in 1995 [24] and by Kennedy and Eberhart in 1995 [25], respectively. Diversity in population to explore the local search is preserved in DE algorithm. But the limitation of DE is the lack of memory which may make the solution to trap in local optima. In PSO algorithm, each particle has a memory and social collaboration which make them capable of remembering the best position ever visited by them. But loss of variance in PSO technique may show inconsistency in few solutions and more probability of trapping in local optima. Therefore, a hybrid of DE and PSO is investigated to have a good balance between exploration and exploitation. Sahu et al., [23] have reported a hybrid DE-PSO algorithm pertaining better transient performance compared to DE and PSO in LFC study. In view of the above, this paper deals with DEPSO for tuning of Fuzzy PID controller parameters for load frequency control (LFC) of multi source multi area interconnected power system. The proposed load frequency controller is designed to stabilize the frequency deviations of both areas of interconnected 
system considering physical constraints such as governor dead band (GDB), reheat turbine and generation rate constraint (GRC) in coordination with the Redox Flow Energy Storage System (RFESS) and the SSSC. The dynamic responses of the overall system have been improved by the proposed controller when compared with some recently published approaches such as output feedback optimal controller [6] and genetic algorithm tuned Integral controller [18] for the same power system.

Followed by short introduction the rest of the paper is structured as follows: the modeling of the interconnected power system is presented in Section 2. Section 3 and section 4 explains the linearized model of SSSC and Energy Storage System, respectively. The controller structure and objective function has been discussed in Section 5. Section 6 describes proposed optimization technique. Section 7 presents the analysis of results. Finally conclusion is being provided in Section 8.

\section{System Investigated}

The system under study is a two area multi source interconnected power system. It includes reheat thermal, hydro and gas generating units in each area [6]. The non-linearity such as GDB and GRC are considered in the system to make it more realistic power system. The transfer function model of the proposed system is shown in Figure 1 for simulation and LFC study. The system parameters are given in Appendix.

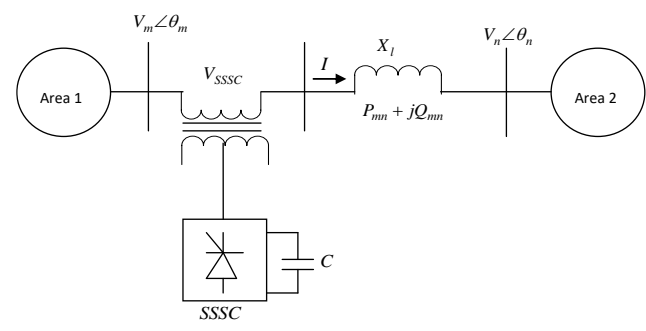

Figure 2. Schematic Diagram of SSSC Connected in Series with the Tie-line

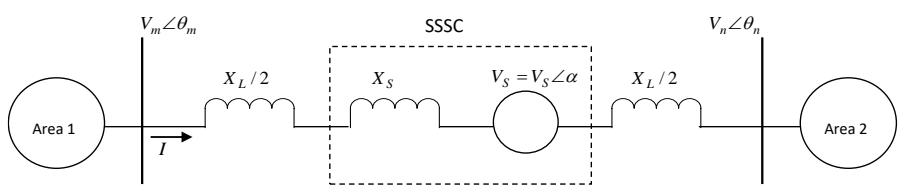

Figure 3. Equivalent Circuit of SSSC Connected in Series with the Tie-line

\section{Modeling of Static Synchronous Series Compensator (SSSC) for LFC}

The SSSC belongs to the family of FACTs devices. It is installed in series with the power transmission lines. It has the potential to switch over its reactance value from capacitive to inductive and effectively control the power flow. It is installed in series with the tie-line for frequency stabilization of interconnected power system. The schematic diagram of SSSC added in series with the tie-line is shown in Figure 2. Equivalent circuit diagram of SSSC is shown in Figure 3. The SSSC is represented by a series connected voltage source $V_{s}$ accompanies by a transformer leakage reactance $X_{s}$. The phasor diagram of the system taking into account the operating condition of SSSC as $V_{s}=0$ is shown in Figure 4 (a) and $V_{s}$ in Figure 4 (b).

The controller to change the SSSC voltage can be expressed as [17-18],

$$
\Delta V_{s}=\left(\frac{1+T_{1} s}{1+T_{2} s}\right)\left(\frac{1+T_{3} s}{1+T_{4} s}\right)\left(\frac{K_{2}}{1+T_{S S S C} s}\right) \Delta \operatorname{Error}(s)
$$


If the frequency deviation $\Delta F_{1}(s)$ is sensed, it can be used as the control signal (i.e., $\Delta$ Error $\left.=\Delta F_{1}(s)\right)$ to the SSSC unit to control $V_{s}$ which will alter the tie-line power flow between two areas and assist in stabilizing the frequency oscillation. Thus,

$$
\Delta P_{\text {tie }}(s)=\frac{2 \pi T_{12}}{s}\left[\Delta F_{1}(s)-\Delta F_{2}(s)\right]+K_{1}\left(\frac{1+T_{1} s}{1+T_{2} s}\right)\left(\frac{1+T_{3} s}{1+T_{4} s}\right)\left(\frac{K_{2}}{1+T_{S S S C} s}\right) \Delta F_{1}
$$

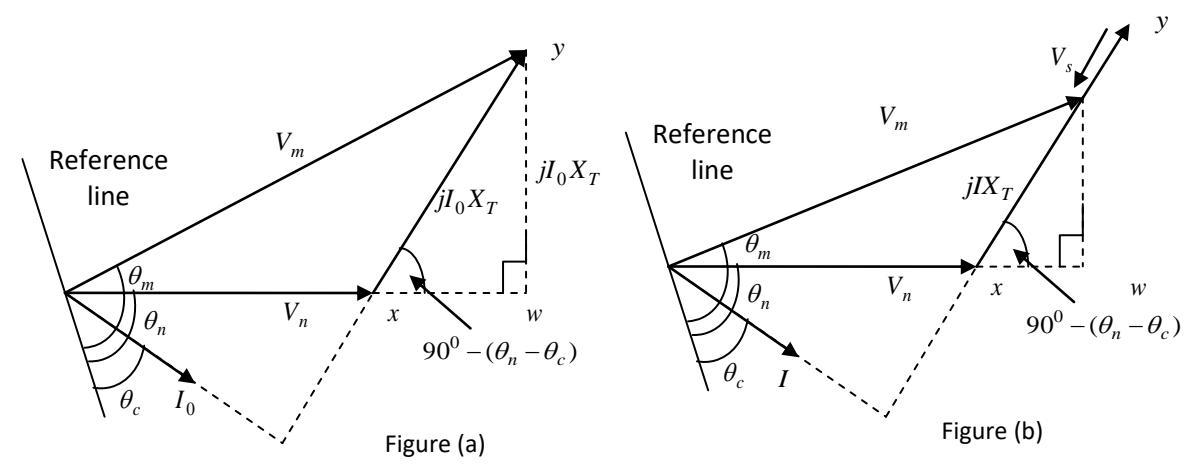

Figure 4(a). Phasor Diagram when Magnitude of Injected Voltage is Zero, (b). Phasor Diagram when Voltage $V_{s}$ Lagging $I$ by $90^{\circ}$

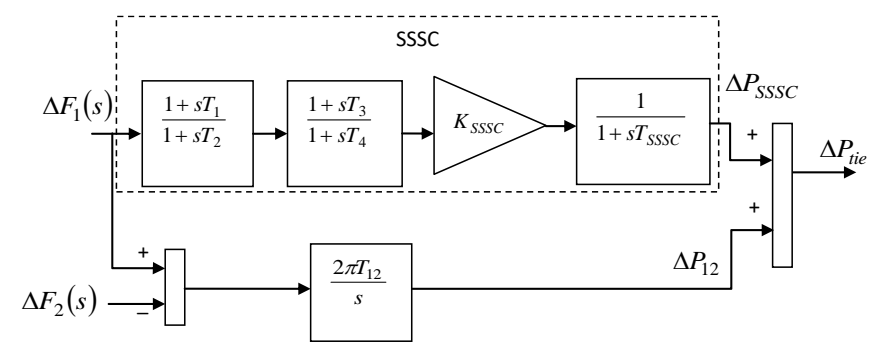

Figure 5. Structure of SSSC as a Frequency Controller

$$
\Delta P_{\text {tie }}=\frac{2 \pi T_{12}}{s}\left[\Delta F_{1}(s)-\Delta F_{2}(s)\right]+\left(\frac{1+T_{1} s}{1+T_{2} s}\right)\left(\frac{1+T_{3} s}{1+T_{4} s}\right)\left(\frac{K_{S S S C}}{1+T_{S S S C} s}\right) \Delta F_{1}
$$

Where, $K_{\text {SSSC }}=K_{1} K_{2}$

$$
\begin{aligned}
& \Delta P_{\text {tie }}(s)=\Delta P_{12}(s)+\Delta P_{S S S C}(s) \\
& \text { Where, } \Delta P_{S S S C}(s)=\left(\frac{1+T_{1} s}{1+T_{2} s}\right)\left(\frac{1+T_{3} s}{1+T_{4} s}\right)\left(\frac{K_{S S S C}}{1+T_{S S S C} s}\right) \Delta F_{1}(s)
\end{aligned}
$$

The structure of SSSC frequency stabilizers consists of the stabilization gain $\left(K_{\text {SSSC }}\right)$ block and the phase compensation block with time constants $T_{1}, T_{2}, T_{3}$ and $T_{4}$ which provides the appropriate phase-lead characteristics to compensate the lag between input and the output signals. The detailed structure of SSSC in series with tie line is provided in Figure 5 .

\section{Modeling of Redox Flow Batteries (RFBs)}

Redox Flow Batteries (RFBs) are rechargeable batteries equivalent to SMES. Its popularity is increasing due to its numerous advantages, such as, long service life, quick 
start up, ease in maintenance and suitability for high capacity systems. A sulphuric acid solution containing vanadium ions is used as the positive and negative electrolytes. The solutions are stored in respective tanks and circulated to battery cell. The block diagram of RFB is shown in Figure 6(a). The chemical reactions occurring in the battery cell during charging and discharging can be expressed with the following equations [18].
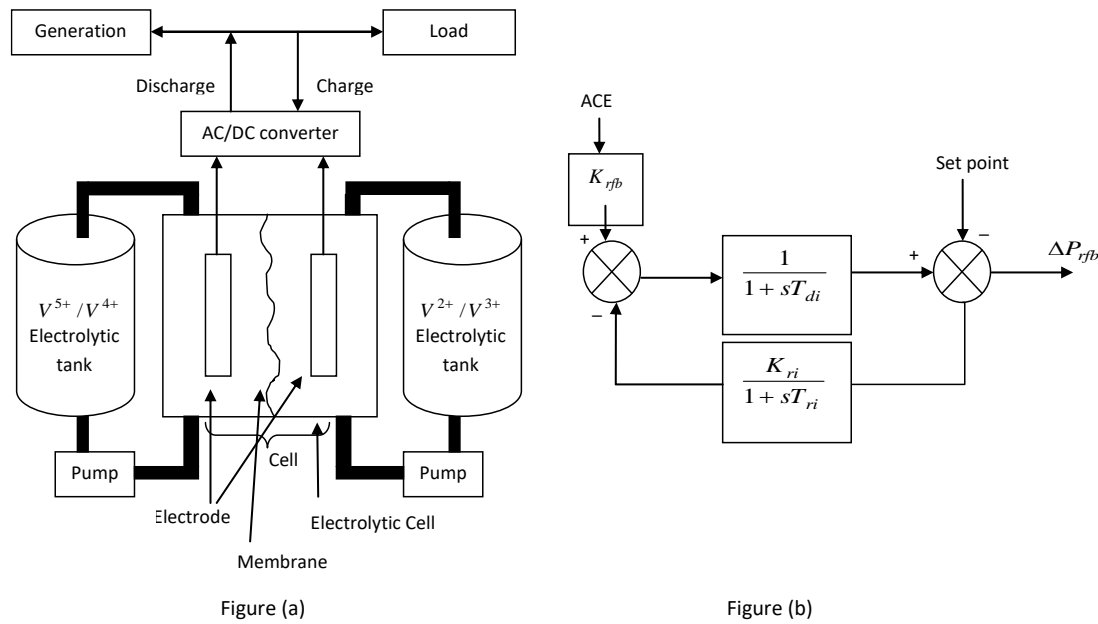

\section{Figure 6 (a). Block Diagram of Redox Flow Battery (RFB), (b). Structure of RFB as a Frequency Controller}

Positive Electrode:

$$
V^{4+} \Leftrightarrow V^{5+}+e^{-} \text {(Charging and discharging mode) }
$$

Negative Electrodes:

$$
V^{3+}+e^{-} \Leftrightarrow V^{2+} \text { (Charging and discharging mode) }
$$

In the present work, RFB have been integrated in LFC study to improve the system response in occurrence of small load perturbation. RFBs are capable of ensuring a very fast response; hence it can eliminate electromechanical oscillation of power system. Area control error (ACE) feeds directly as the controlling input signal to the RFB units. The RFB can be charged during the off-peak periods and the stored energy is used during the peak periods or sudden load changes. The dual converter is used for performing both ACDC and DC-AC conversions. A transfer function model of RFB for frequency stabilization is shown in Figure 6(b) [18]. The equation for participation of RFBs in LFC of system can be presented as,

$$
\Delta P_{r f b}(s)=\left\{\left(A C E \times K_{r f b}\right)-\left(\frac{K_{r i}}{1+T_{r i} s}\right)\right\}\left(\frac{1}{1+T_{d i} s}\right)-(\text { set value })
$$

Where, $($ set value $=0)$ and other parameters are provided in Appendix.

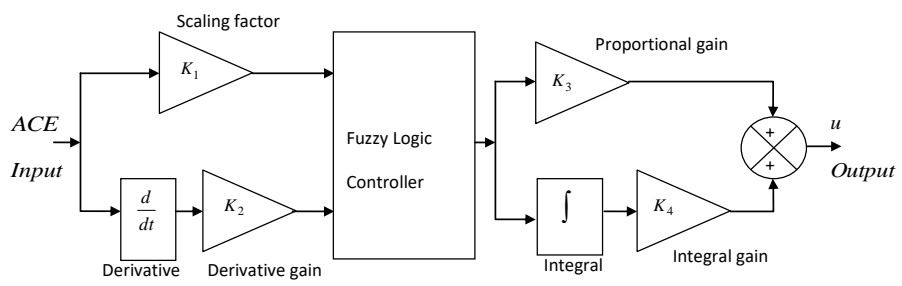

Figure 7. Structure of Proposed Fuzzy PID Controller 


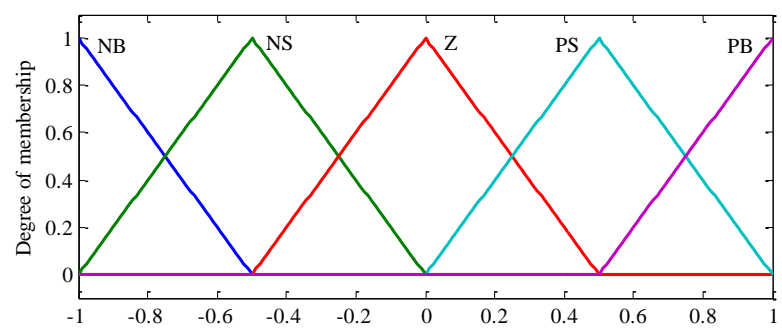

Figure 8. Membership Functions for Error, Error Derivative and FLC Output

Table 1. Fuzzy Rules for the Inputs and Outputs

\begin{tabular}{|c|c|c|c|c|c|}
\hline \multirow{2}{*}{ ACE } & \multicolumn{5}{|c|}{$\Delta \mathbf{A C E}$} \\
\cline { 2 - 6 } & $\mathbf{N B}$ & $\mathbf{N S}$ & $\mathbf{Z}$ & $\mathbf{P S}$ & $\mathbf{P B}$ \\
\hline NB & NB & NB & NB & NS & Z \\
\hline NS & NB & NB & NS & Z & PS \\
\hline $\mathbf{Z}$ & NB & NS & Z & PS & PB \\
\hline PS & NS & Z & PS & PB & PB \\
\hline PB & PB & Z & PS & PB & PB \\
\hline
\end{tabular}

\section{Controller Structure and Objective Function}

The structure of the Fuzzy PID controller is shown in Figure 7 [22]. An identical controller is employed in each area. The two inputs to the controllers are the respective area control error (ACE) and its derivatives. Fuzzy PID controller integrates fuzzy proportion-integral (PI) and fuzzy proportional-derivative (PD) controllers. The input scaling factors are $K_{1}$ and $K_{2}$ and the output scaling factors are $K_{3}$ and $K_{4}$. Triangular membership functions are used with five fuzzy linguistic variables such as NB (negative big), NS (negative small), Z (zero), PS (positive small) and PB (positive big) for both the inputs and the output. Membership functions for error, error derivative and FLC output are depicted in Figure 8. Mamdani fuzzy inference engine is chosen for the present work. The two-dimensional rule base for error, error derivative and FLC output are given in Table 1.

In the design of the controller parameters, the objective function is first defined based on the desired specifications and constraints. Usual output specifications in time domain are rise time, settling time, peak overshoot and steady state errors. There are four different types of performance criteria normally considered in the control design, namely the integral of absolute error (IAE), integral of time multiplied absolute error (ITAE), integral of squared error (ISE) and integral of time multiplied squared error (ITSE). Among these ITAE gives better performance compared to others, therefore it is used as objective function to find the optimum value of the controller parameters. The objective function $J$ for controller parameters optimization of the interconnected power system is depicted below.

$$
J=I T A E=\int_{0}^{t_{\text {sin }}}\left(\left|\Delta F_{1}\right|+\left|\Delta F_{2}\right|+\left|\Delta P_{\text {tie }}\right|\right) \cdot t \cdot d t
$$

Where, $\Delta F_{1}$ and $\Delta F_{2}$ are the system frequency deviations; $\Delta P_{\text {tie }}$ is the incremental variation in tie line power. $t_{\text {sim }}$ is the simulation time. 


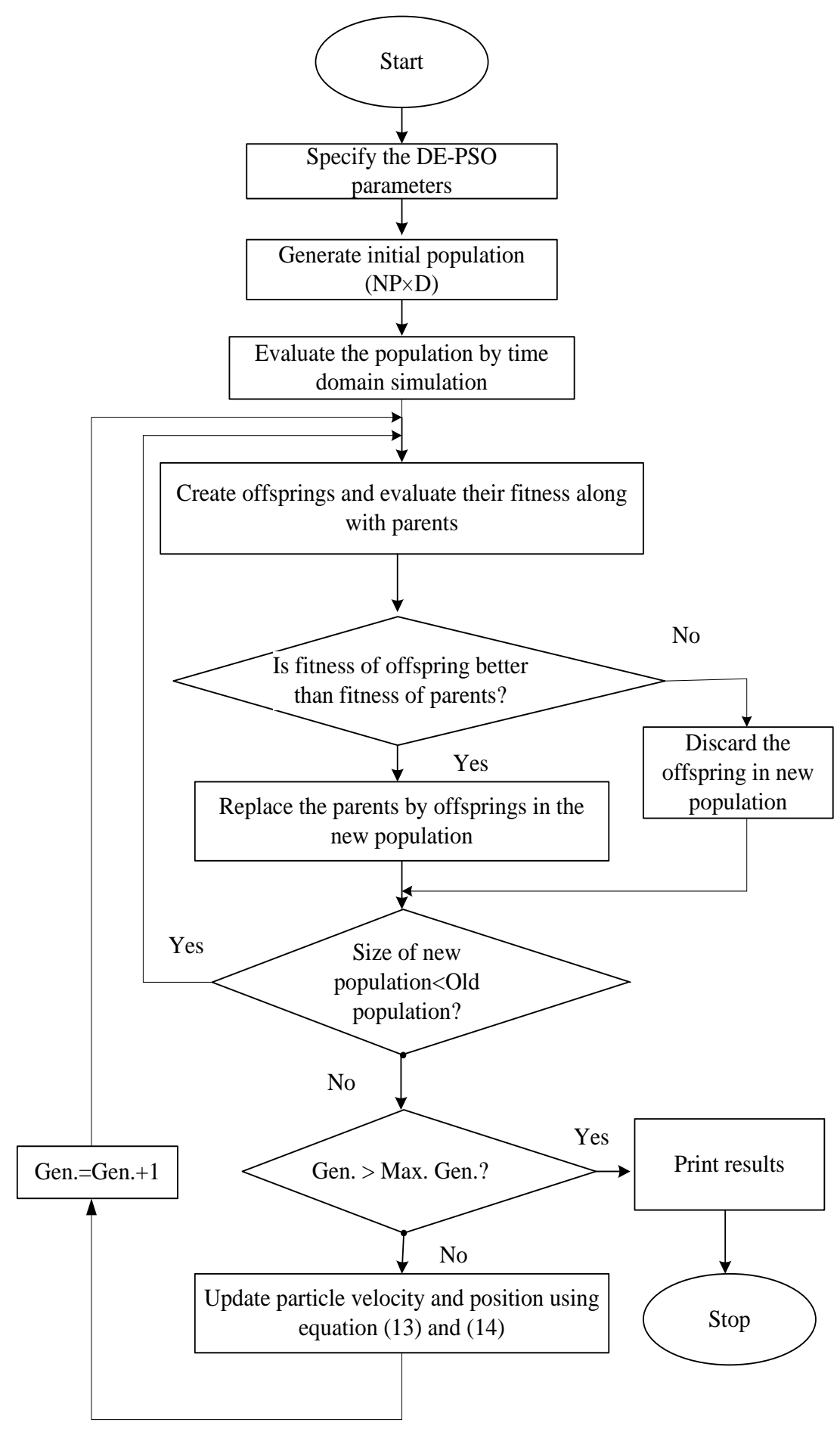

Figure 9. Flowchart of Hybrid DE-PSO Algorithm

\section{Overview of DE-PSO Technique}

In this paper, a hybrid DEPSO algorithm is used to find the optimal parameters of the Fuzzy PID controller. A hybrid of DE and PSO has the feature of diversity, individual cognition and social collaboration of particles in the algorithm which makes the algorithm reliable and efficient. The flowchart for hybrid DE-PSO algorithm is shown in Figure 9. Different computational steps adopted in this hybrid DE-PSO [23] algorithm are as follows: 
Step 1: Initialize a random population of size $[N P \times D]$

Where, row represents population $N P$ and column represents dimension $D$.

Step 2: Initialize the velocity randomly for each particle to be used in PSO algorithm.

Step 3: DE operation

(i) Generate the donor vector $V_{i}$ from parent vectors

$$
V_{i}=X_{i, r_{1}}+F \times\left(X_{i, r_{2}}-X_{i, r_{3}}\right)
$$

Where $r_{1}, r_{2}$ and $r_{3}$ are three distinct integers chosen between 1 and NP.F is the scaling factor.

Calculate the offspring vector $U_{i}$ to perform crossover operation

$$
U_{i}=V_{i}, \quad \text { if } \quad \operatorname{rand}(0,1) \leq C R \quad \text { or } \quad j=j_{\text {rand }}
$$

$U_{i}=X_{i}$, otherwise, where $C R$ is the crossover rate.

Choose the target vector to be used in selection process as in equation (12),

$$
X_{i}= \begin{cases}U_{i}, & \text { if } f\left(U_{i}\right) \leq f\left(X_{i}\right) \\ X_{i}, & \text { otherwise }\end{cases}
$$

Where, $f=J$ is the function to be minimized.

(ii) Identify the local best $\left(P_{\text {best }}\right)$ and the global best $\left(P_{\text {gbest }}\right)$.

Step 4: PSO operation

(i) Take $X_{i}$ as the initial population obtained in step (iii) of DE operation.

(ii) Update the velocity of each particle in equation (13),

$$
v_{i}^{i+1}=w v_{i}^{i}+c_{1} \operatorname{rand}_{1}\left(p_{i, \text { best }}^{k}-x_{i}^{k}\right)+c_{2} \operatorname{rand}_{2}\left(p_{i, \text { gbest }}^{k}-x_{i}^{k}\right)
$$

Where $c_{1}$ and $c_{2}$ are acceleration coefficients. $w$ is the inertia weight whose value linearly decreases from 0.9 to 0.4 with iteration. rand $_{1}$ and $r a n d_{2}$ are two random numbers in the range $[0,1]$.

(iii) Update the swarm position using equation (14)

$$
X_{i, \text { new }}=X_{i}+V_{i}
$$

(iv) Evaluate the fitness of objective function.

(v) Select the best solutions for next iteration by comparing the fitness using equation (15).

$$
X_{i}^{G+1}= \begin{cases}X_{i, \text { new }}, & \text { if } \quad f\left(X_{i, \text { new }}\right) \leq f\left(X_{i}\right) \\ X_{i}, & \text { otherwise }\end{cases}
$$

Step 5: Increment the generation count.

Step 6: Repeat steps 3-5 until stopping criteria are met.

\section{Results and Discussions}

The present work has been implemented in MATLAB/SIMULINK environment and the controller parameters are tuned using hybrid DE-PSO algorithm. Series of simulations were performed judiciously to select the gains of controller. The simulation was repeated 30 times and the best final solution among the 30 runs is selected as proposed controller parameters. The best final solutions obtained in the 30 runs are considered as optimal solution shown in Table 2 for the system. 


\subsection{Optimal Controller Parameters Tuning and System Dynamic Performance Analysis}

The optimal parameter values of the proposed algorithm are selected as $F=0.5, C R=$ 0.5 , the number of population $N P=30$, dimension $D=12$ (Fuzzy PID controller) in the present work. $D$ varies with the type of controller used. Velocities upper and lower limits as $V_{\min }=V_{\max }=20 \%$ of search space [0-2], $w_{\max }=0.9, w_{\min }=0.4$, maximum iteration iter $_{\max }=100, c_{1}=2$ and $c_{2}=2$ for the power system.

A two area multi source power system model incorporated with SSSC and RFB is developed for LFC study. Time domain simulations have been carried out for the system subjected to $0.01 \mathrm{pu}$ step load perturbation (SLP) in area-1. In this study four different types of controllers like I, PI, PID and FLC are tested for LFC and their results are compared as shown in Figure 10(a)-(c). The parameters of the above controllers are optimized by the proposed hybrid DE-PSO algorithm using ITAE as objective function.


Figure 10(a). Frequency Deviation in Area-1, (b). Frequency Deviation in area-2, (c). Tie-line Power Flow Deviation of Interconnected Power System

Subjected to Step Load Perturbation of 0.01 pu in Area-1 and their Comparison for DE-PSO Optimized Different Controllers

Table 2 presents the gains of optimal control parameters of the various controllers obtained by proposed algorithm. The different performance indices like settling time, minimum undershoot (MUS) and maximum overshoot (MOS) are presented in Table 3. Investigations inform that I, PI and PID controllers provide comparatively same response whereas Fuzzy PID controller provides much better response than the other controllers. 
The dynamic responses of the overall system have been improved significantly by the proposed Fuzzy PID controller when compared to newly published works such as genetic algorithm tuned Integral controller [18] and output feedback optimal controller [6] for the same interconnected power system subjected to 0.01 pu SLP in area-1, as shown in Figures 11 (a) - (c).
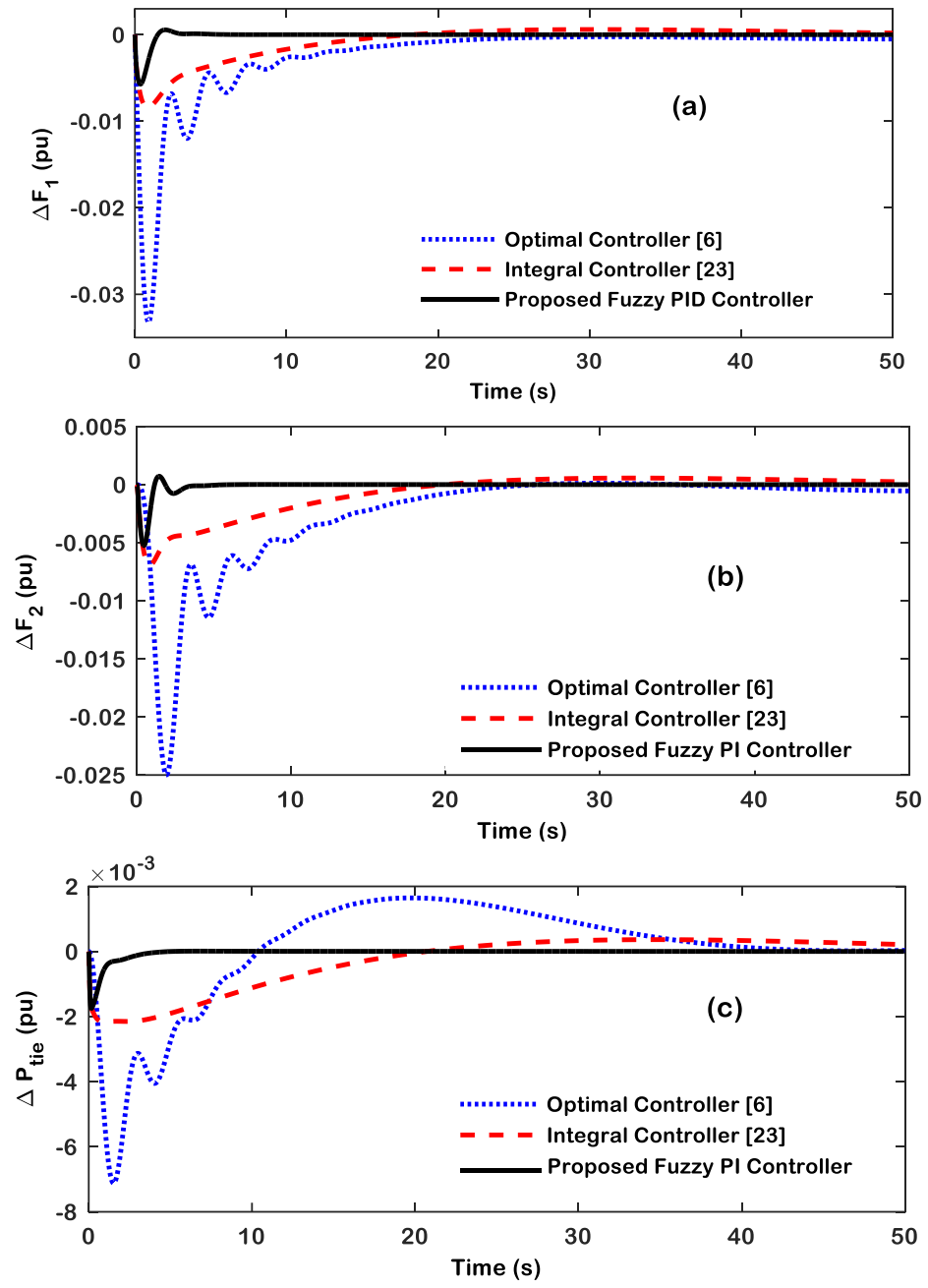

Figure 11(a). Frequency Deviation in area-1, (b). Frequency Deviation in area-2, (c). Tie-line Power Flow Deviation of Interconnected Power System Subjected to Step Load Perturbation of $0.01 \mathrm{pu}$ in area-1 and their Comparison for Proposed DE-PSO Optimized Fuzzy PID Control Scheme with GA Optimized Integral Control Scheme [18] and Optimal Control Scheme [6]

The various comparative performance indices such as settling time, maximum overshoot and objective functions are provided in Table 4 taking 100 seconds as simulation time. From Table 4, it is clear that the settling time, minimum undershoot of frequency deviation of area $1\left(\Delta F_{1}\right)$, area $2\left(\Delta F_{2}\right)$ and tie line power deviations $\left(\Delta P_{\text {tie }}\right)$ are lesser by the proposed Fuzzy-PID controllers than that of genetic algorithm tuned Integral controller [18] and output feedback optimal controller [6]. Also it is clear from Table 4 that the proposed controller outperforms to others in terms of minimum objective function values. 
Table 2. DEPSO Optimized Different Controller Parameters of Multi-Source Multi-Area Power System

\begin{tabular}{|c|c|c|c|c|c|c|}
\hline Methods & & Area1 & & & Area2 & \\
\hline $\begin{array}{c}\text { DEPSO } \\
\text { optimized } \\
\text { Controller }\end{array}$ & Thermal & Hydro & Gas & Thermal & Hydro & Gas \\
\hline & $K_{1}=1.0825$ & $K_{1}=0.1569$ & $K_{1}=1.5785$ & $K_{1}=1.0825$ & $K_{1}=0.1569$ & $K_{1}=1.5785$ \\
\hline $\begin{array}{c}\text { Fuzzy } \\
\text { PID }\end{array}$ & $K_{2}=1.690$ & $K_{2}=0.0141$ & $K_{2}=0.7728$ & $K_{2}=1.690$ & $K_{2}=0.0141$ & $K_{2}=0.7728$ \\
\hline $\begin{array}{c}\text { PID } \\
\text { Controller }\end{array}$ & $K_{3}=1.9184$ & $K_{3}=1.2355$ & $K_{3}=0.6210$ & $K_{3}=1.9184$ & $K_{3}=1.2355$ & $K_{3}=0.6210$ \\
\hline & $K_{4}=0.2893$ & $K_{4}=1.2441$ & $K_{4}=1.8705$ & $K_{4}=0.2893$ & $K_{4}=1.2441$ & $K_{4}=1.8705$ \\
\hline $\begin{array}{c}\text { PID } \\
\text { Controller }\end{array}$ & $\begin{aligned} K_{P} & =0.1358 \\
K_{I} & =2.4802 \\
K_{D} & =0.6271\end{aligned}$ & $\begin{array}{r}K_{P}=2.3167 \\
K_{I}=2.9244 \\
K_{D}=-0.5426\end{array}$ & $\begin{array}{c}K_{P}=2.6956 \\
K_{I}=2.3839 \\
K_{D}=-0.6396\end{array}$ & $\begin{array}{c}K_{P}=- \\
0.9790 \\
K_{I}=0.1205 \\
K_{D}=0.4842\end{array}$ & $\begin{aligned} K_{P} & =0.9338 \\
K_{I} & =1.9201 \\
K_{D} & =1.2769\end{aligned}$ & $\begin{array}{c}K_{P} \\
=1.5713 \\
K_{I}=0.4251 \\
K_{D} \\
=1.9599\end{array}$ \\
\hline $\begin{array}{c}\text { PI } \\
\text { Controller }\end{array}$ & $\begin{aligned} K_{P} & =1.8210 \\
K_{I} & =0.6478\end{aligned}$ & $\begin{array}{l}K_{P}=2.0170 \\
K_{I}=2.7214\end{array}$ & $\begin{array}{l}K_{P}=2.9169 \\
K_{I}=2.9856\end{array}$ & $\begin{aligned} K_{P} & =0.3848 \\
K_{I} & =2.9690\end{aligned}$ & $\begin{aligned} K_{P} & =2.3772 \\
K_{I} & =1.8017\end{aligned}$ & $\begin{array}{c}K_{P} \\
=1.4658 \\
K_{I}=2.0831 \\
\end{array}$ \\
\hline $\begin{array}{c}\text { Integral } \\
\text { Controller }\end{array}$ & $K_{I}=1.5133$ & $K_{I}=1.9910$ & $K_{I}=1.9249$ & $K_{I}=1.0701$ & $K_{I}=1.9277$ & $K_{I}=0.2313$ \\
\hline
\end{tabular}

Table 3. Performance Evaluation of Different DEPSO Optimized Controllers by Settling Time, Minimum Undershoot and Maximum Overshoot

\begin{tabular}{|c|c|c|c|c|c|}
\hline \multicolumn{2}{|c|}{$\begin{array}{c}\text { Controllers \& } \\
\text { Parameters }\end{array}$} & $\begin{array}{c}\text { Proposed Fuzzy } \\
\text { PID Controller } \\
\text { Value }\end{array}$ & $\begin{array}{c}\text { PID } \\
\text { Controller } \\
\text { Value } \\
\end{array}$ & $\begin{array}{c}\text { PI } \\
\text { Controller } \\
\text { Value }\end{array}$ & $\begin{array}{c}\text { Integral } \\
\text { Controller } \\
\text { Value }\end{array}$ \\
\hline \multirow{3}{*}{$\begin{array}{l}\text { Settling times } \\
(2 \% \text { band }) \\
\text { (seconds) }\end{array}$} & $\Delta f_{1}$ & 2.59 & 23.18 & 22.77 & 25.75 \\
\hline & $\Delta f_{2}$ & 3.29 & 25.02 & 24.36 & 28.95 \\
\hline & $\Delta P_{T i e}$ & 2.44 & 20.4 & 14.85 & 25.18 \\
\hline \multirow{3}{*}{$\begin{array}{l}\text { MUS } \\
\text { (p.u.) }\end{array}$} & $\Delta f_{1} \times 10^{-3}$ & 5.2 & 8.84131 & 8.16617 & 8.44184 \\
\hline & $\Delta f_{2} \times 10^{-3}$ & 5.1 & 7.47549 & 7.00190 & 6.97510 \\
\hline & $\Delta P_{T i e} \times 10^{-3}$ & 1.75 & 2.25275 & 2.11161 & 2.17442 \\
\hline \multirow{3}{*}{$\begin{array}{l}\text { MOS } \\
\text { (p.u.) }\end{array}$} & $\Delta f_{1} \times 10^{-3}$ & 0.56554 & 0.50225 & 0.38104 & 0.67324 \\
\hline & $\Delta f_{2} \times 10^{-3}$ & 0.72648 & 0.41834 & 0.35574 & 0.53688 \\
\hline & $\Delta P_{T i e} \times 10^{-3}$ & 0.01008 & 0.24568 & 0.20281 & 0.34763 \\
\hline
\end{tabular}



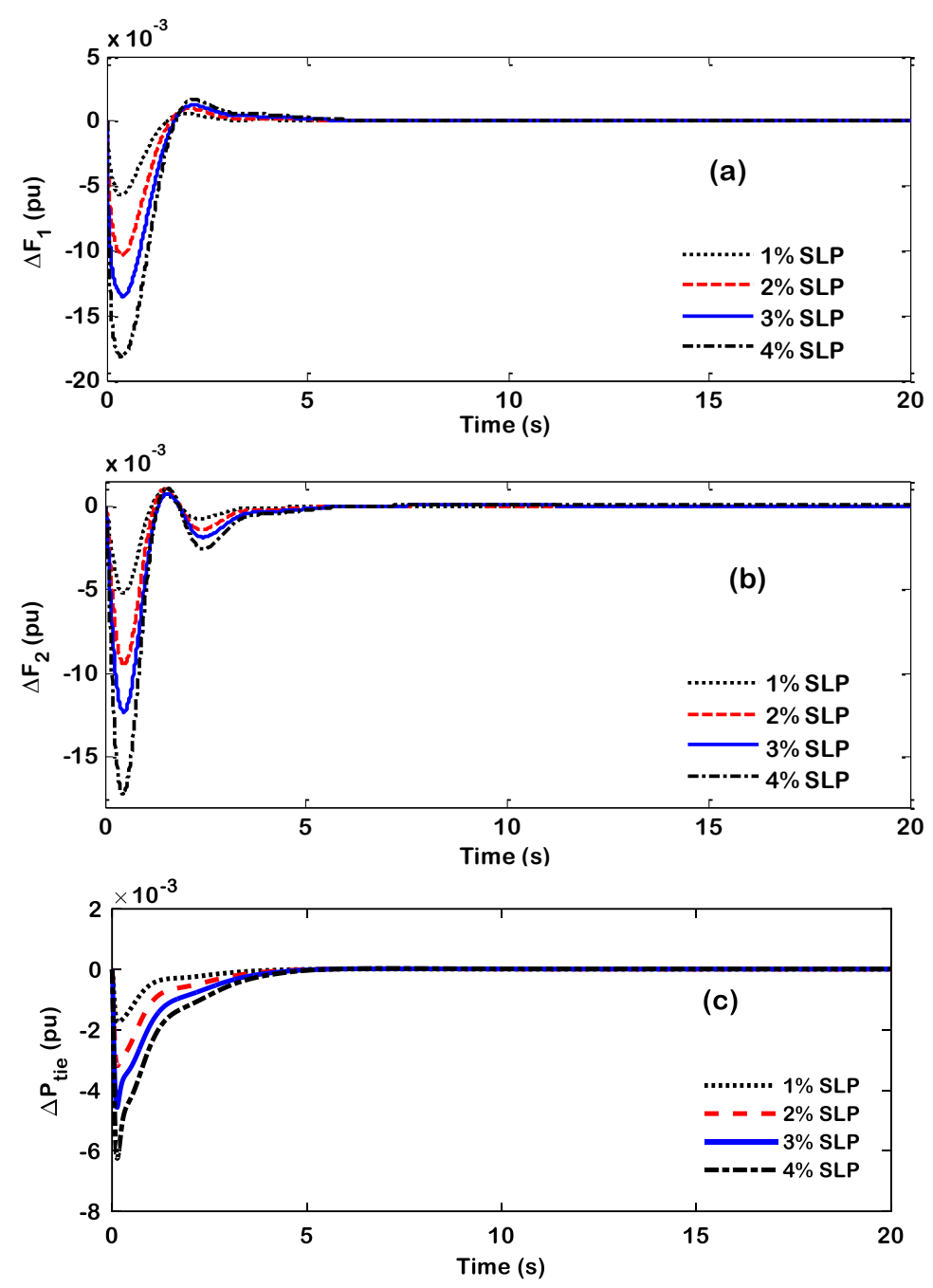

Figure 12(a). Frequency Deviation of Area-1, (b). Frequency Deviation of area-2, (c). Tie-line Power Flow Deviation with Different SLP in Area-1

Table 4. Performance Criteria for Two Area Multi-Source Power System with SSSC and RFB

\begin{tabular}{|c|c|c|c|c|}
\hline $\begin{array}{c}\text { Objective Function \& } \\
\text { Parameters }\end{array}$ & $\begin{array}{c}\text { Proposed Fuzzy } \\
\text { PID Controller } \\
\text { Value }\end{array}$ & $\begin{array}{c}\text { Integral } \\
\text { Controller [32] }\end{array}$ & $\begin{array}{c}\text { Optimal } \\
\text { Controller [11] } \\
\text { Value }\end{array}$ \\
\hline \multicolumn{2}{|c|}{ ITAE } & 0.0358 & 2.2372 & 5.8139 \\
\hline \multicolumn{2}{|c|}{ ISE } & $3.68 \times 10^{-5}$ & 0.0002 & 0.0029 \\
\hline \multicolumn{2}{|c|}{ ITSE } & $1.96 \times 10^{-5}$ & 0.002 & 0.01 \\
\hline \multicolumn{2}{|c|}{ IAE } & 0.0128 & 0.1565 & 0.346 \\
\hline \multirow{2}{*}{$\begin{array}{c}\text { Settling times } \\
\text { (2\% band) } \\
\text { (seconds) }\end{array}$} & $\Delta f_{1}$ & 2.79 & 22.03 & 28.12 \\
\cline { 2 - 5 } & $\Delta f_{2}$ & 3.29 & 23.45 & 30.21 \\
\hline \multirow{2}{*}{$\begin{array}{c}\text { MUS } \\
\text { (p.u.) }\end{array}$} & $\Delta P_{T i e}$ & 2.44 & 37.51 & 37.93 \\
\cline { 2 - 5 } & $\Delta f_{2}$ & 0.0055 & 0.0073 & 0.0327 \\
\cline { 2 - 5 } & $\Delta P_{T i e}$ & 0.0051 & 0.0078 & 0.0236 \\
\hline
\end{tabular}




\subsection{Sensitivity Analysis}

Sensitivity analysis is performed to study the robustness of the proposed Fuzzy PID controller. Sensitivity is the capability of a system to perform satisfactorily while system variables are varied within a certain tolerance limit. To verify the robustness of the proposed controller SLPs are varied from 1-4\% with a hike of $1 \%$ and its transient responses such as $\Delta F_{1}, \Delta F_{2}$ and $\Delta P_{\text {tie }}$ are shown in Figures 12(a)-(c), respectively. Further, the dynamic response of the system is analysed when subjected to random loading. The nature of random load pattern applied to the system is shown in Figure 13. The frequency deviations of two areas $\Delta F_{1}$ and $\Delta F_{2}$ by the application of random loading are depicted in Figures 14(a)-(b). From Figures 12 and 14, it is clear that the proposed controller and the system with coordinated operation of SSSC and RFB is quite robust.

Table 5. Sensitivity Analysis

\begin{tabular}{|c|c|c|c|c|c|c|c|c|}
\hline \multirow{2}{*}{$\begin{array}{c}\text { Parameter } \\
\text { variation }\end{array}$} & \multirow{2}{*}{$\begin{array}{c}\text { \% } \\
\text { Change }\end{array}$} & \multicolumn{6}{|c|}{ Settling time } & \multicolumn{3}{c|}{ Peak overshoot } & \multirow{2}{*}{ ITAE } \\
\cline { 3 - 9 } & & $\Delta f_{1}$ & $\Delta f_{2}$ & $\Delta P_{T i e}$ & $\Delta f_{1} \times 10^{-4}$ & $\Delta f_{2} \times 10^{-4}$ & $\Delta P_{T i} \times 10^{-4}$ & \\
\hline Nominal & 0 & 2.8 & 3.3 & 2.44 & 5.517358 & 6.8426 & 0.1022 & 0.0358 \\
\hline \multirow{2}{*}{$\begin{array}{c}\text { Loading } \\
\text { condition }\end{array}$} & +25 & 2.8 & 3.3 & 2.44 & 5.440034 & 6.5998 & 0.1030 & 0.0357 \\
\cline { 2 - 9 } & -25 & 2.8 & 3.3 & 2.44 & 5.598869 & 7.0896 & 0.1014 & 0.0358 \\
\hline \multirow{2}{*}{$T_{G}$} & +25 & 2.8 & 3.3 & 2.44 & 5.517358 & 6.8426 & 0.1022 & 0.0358 \\
\cline { 2 - 9 } & -25 & 2.8 & 3.3 & 2.44 & 5.517358 & 6.8426 & 0.1022 & 0.0358 \\
\hline \multirow{2}{*}{$T_{T}$} & +25 & 2.8 & 3.3 & 2.44 & 5.517358 & 6.8426 & 0.1022 & 0.0358 \\
\cline { 2 - 8 } & -25 & 2.8 & 3.3 & 2.44 & 5.517358 & 6.8426 & 0.1022 & 0.0358 \\
\hline \multirow{2}{*}{$T_{R H}$} & +25 & 2.95 & 3.34 & 2.4 & 5.007463 & 4.5403 & 0.0945 & 0.0401 \\
\cline { 2 - 8 } & -25 & 2.64 & 3.21 & 2.51 & 6.555069 & 11.1357 & 0.1136 & 0.0300 \\
\hline \multirow{2}{*}{$T_{12}$} & +25 & 2.69 & 3.2 & 2.43 & 5.972079 & 6.1021 & 0.1470 & 0.0350 \\
\cline { 2 - 7 } & -25 & 2.95 & 3.42 & 2.37 & 4.852559 & 7.8157 & 0.0617 & 0.0368 \\
\hline
\end{tabular}

The robustness of power system is studied with vast variation of the system parameters such as governor time constant $T_{G}$ of both areas, turbine time constant $T_{T}$ of both areas, tie line power coefficient $T_{12}$ and hydro governor time constant $T_{R H}$ of both areas simultaneously in the range of $+25 \%$ and $-25 \%$ from their nominal values. The sensitivity is studied with wide changes in the operating condition and system parameters as presented in Table 5. It can be seen that the proposed strategy affords satisfactorily control performance at nominal parameters and need not be rescheduled for vast variation in the system parameters.

\subsection{System Investigation with Eigen Values}

In this literature various controllers are investigated for LFC study. The closed loop system stability is said to be stable if all the eigen values are located to the left half of the s-plane. The eigen values evaluated for the system are presented in Table 6 . All the eigen values are located in the left half of the s-plane, because of which the system is stable. It is worthwhile to mention that the system with higher minimum damping ratio (MDR) have better dynamic performance. The MDR value is higher for the proposed system as 0.678 compared with system containing genetic algorithm tuned Integral controller [18] as 0.668 and output feedback optimal controller [6] as 0.1603. It is observed from Table 6 that the stability margin of the considered system with proposed controller significantly improved. 
Table 6. System Modes, Minimum Damping Ratio, for Multi-Source Multi Area Power System

\begin{tabular}{|c|c|c|c|}
\hline Methods & $\begin{array}{c}\text { Proposed DEPSO } \\
\text { tuned } \\
\text { Fuzzy PID Controller }\end{array}$ & $\begin{array}{c}\text { GA tuned } \\
\text { Integral Controller } \\
{[18]}\end{array}$ & $\begin{array}{c}\text { Optimal Controller } \\
{[6]}\end{array}$ \\
\hline $\begin{array}{l}\text { System } \\
\text { Modes }\end{array}$ & $\begin{array}{c}-25.3952+20.2029 \mathrm{i} \\
-25.3952-20.2029 \mathrm{i} \\
-19.6849 \\
-20.0272 \\
-13.0783 \\
-12.5604 \\
-9.0851 \\
-7.2761 \\
-2.0733+2.1918 \mathrm{i} \\
-2.0733-2.1918 \mathrm{i} \\
-1.8725+2.0407 \mathrm{i} \\
-1.8725-2.0407 \mathrm{i} \\
-4.0298 \\
-3.4722 \\
-3.4925 \\
-2.4717+0.7027 \mathrm{i} \\
-2.4717-0.7027 \mathrm{i} \\
-2.5663+0.5397 \mathrm{i} \\
-2.5663-0.5397 \mathrm{i} \\
-1.3336 \\
-1.3923 \\
-0.5716 \\
-0.1344 \\
-0.0432 \\
-0.0343 \\
-0.0967 \\
-5.0000 \\
-5.0000\end{array}$ & $\begin{array}{c}-25.3921+20.2034 \mathrm{i} \\
-25.3921-20.2034 \mathrm{i} \\
-19.6859 \\
-20.0237 \\
-13.0713 \\
-12.5692 \\
-9.0801 \\
-7.2762 \\
-1.9804+2.2064 \mathrm{i} \\
-1.9804-2.2064 \mathrm{i} \\
-1.9016+1.8308 \mathrm{i} \\
-1.9016-1.8308 \mathrm{i} \\
-4.0300 \\
-3.4876 \\
-3.4630 \\
-2.4602+0.7854 \mathrm{i} \\
-2.4602-0.7854 \mathrm{i} \\
-2.5628+0.5536 \mathrm{i} \\
-2.5628-0.5536 \mathrm{i} \\
-1.4040 \\
-1.3696 \\
-0.5368 \\
-0.1045+0.1159 \mathrm{i} \\
-0.1045-0.1159 \mathrm{i} \\
-0.0861+0.0671 \mathrm{i} \\
-0.0861-0.0671 \mathrm{i} \\
-0.0503 \\
-0.0477 \\
-5.0000 \\
-5.0000 \\
\end{array}$ & $\begin{array}{c}-19.9700 \\
-19.9616 \\
-12.7873 \\
-12.9007 \\
-5.8127 \\
-5.6654 \\
-0.3871+2.3834 \mathrm{i} \\
-0.3871-2.3834 \mathrm{i} \\
-3.9192 \\
-3.8438 \\
-1.0694+1.4806 \mathrm{i} \\
-1.0694-1.4806 \mathrm{i} \\
-2.6177 \\
-1.7729+0.3832 \mathrm{i} \\
-1.7729-0.3832 \mathrm{i} \\
-1.4130 \\
-0.8764 \\
-0.2536 \\
-0.0708+0.1187 \mathrm{i} \\
-0.0708-0.1187 \mathrm{i} \\
-0.1361 \\
-0.0149 \\
-0.0333 \\
-5.0000 \\
-5.0000\end{array}$ \\
\hline MDR & 0.678 & 0.1603 & 0.668 \\
\hline
\end{tabular}

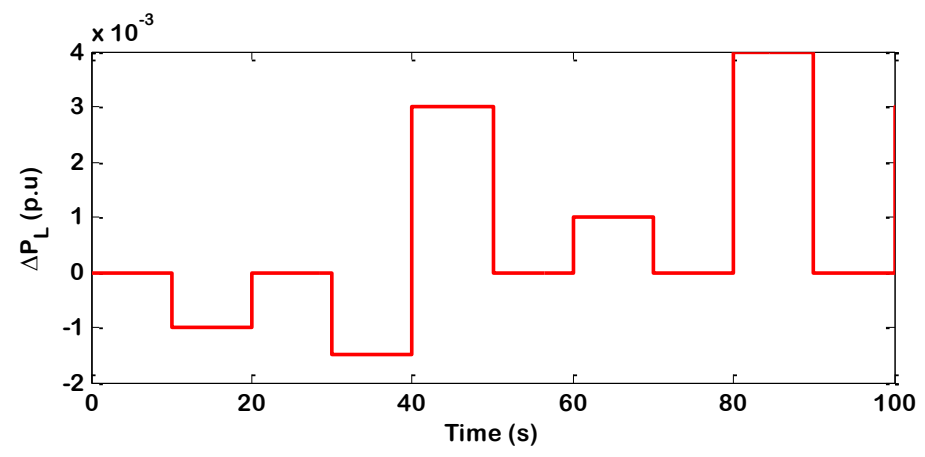

Figure 13. Random Load Pattern with Respect to Time 

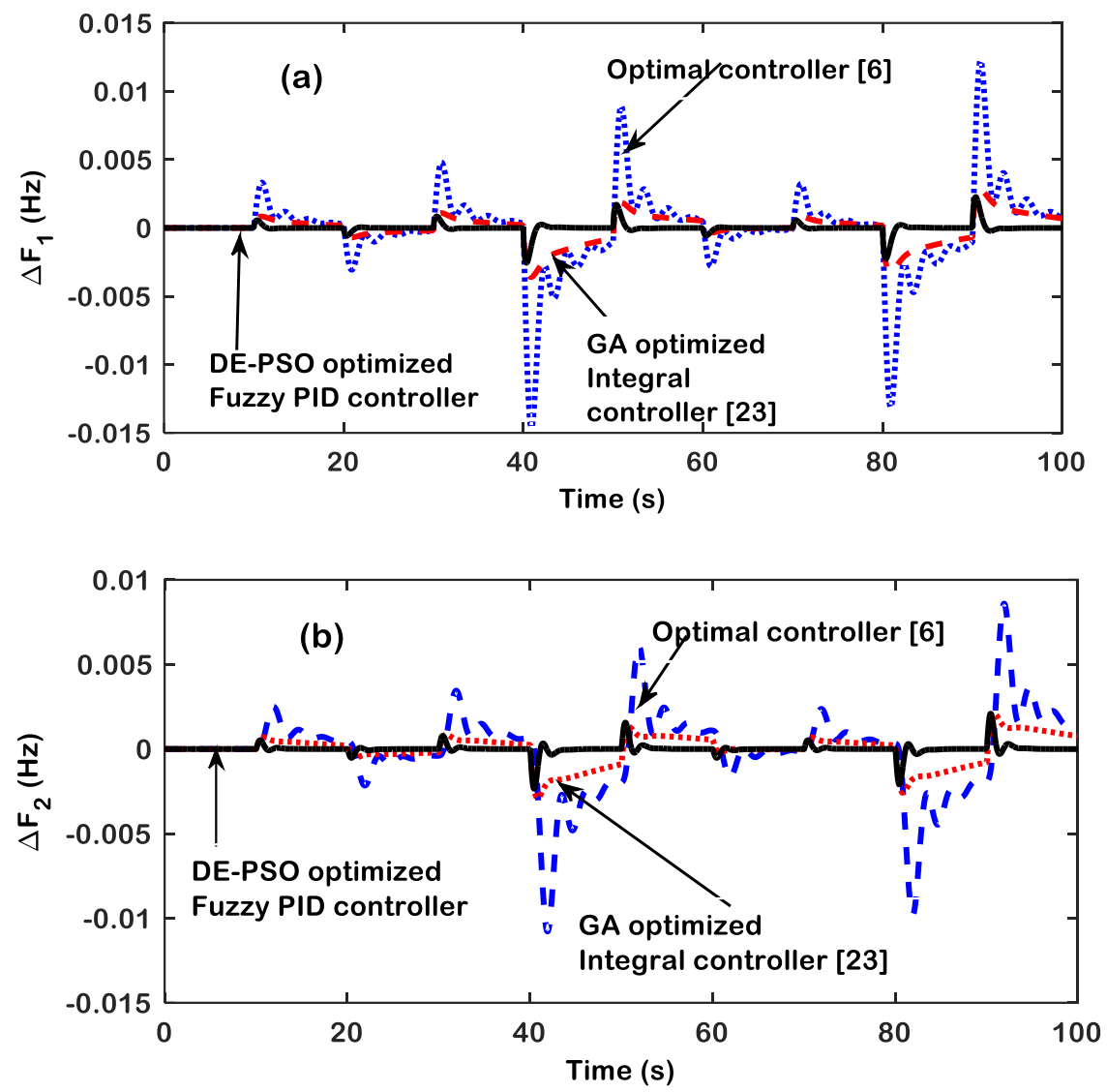

Figure 14(a). Frequency Deviation in Area-1, (b). Frequency Deviation in Area 2 obtained using Optimal Controller, GA Tuned Integral Controller and Proposed DE-PSO Optimized Fuzzy PID Controller vs. Time

\section{Conclusion}

This paper describes the improvement of dynamic performance of the interconnected power system when the proposed Fuzzy PID controller is incorporated with the SSSC and RFB. The system investigated is a realistic multi source two area interconnected power system which includes reheats thermal, hydro and gas generating units in each area. A hybrid DE-PSO algorithm is employed to find the optimal parameter values of the controller taking into account ITAE as objective function. Investigations report that I, PI and PID controllers provide comparatively similar response whereas Fuzzy PID controller gives much better response than others. The superiority of the proposed DE-PSO tuned Fuzzy PID controller is evaluated by comparing with newly published works such as genetic algorithm tuned Integral controller and output feedback optimal controller for the identical power system. The system is investigated for wide variation of step loads and random load. Finally, sensitivity analysis is performed by changing the system parameters and operating conditions from their nominal values. It is seen that the optimum gains of the proposed controller need not be re-optimized even if the system is subjected to vast variation in loading condition and system parameters. It is also clear from sensitivity study that the system is quite robust. The simulation results show that the proposed DEPSO optimized Fuzzy PID controller ensures improved transient as well as steady state of response. 


\section{Appendix:}

The typical values of system under study are given below $[6,18]$ :

A.1 Power system: $f=60 \mathrm{~Hz} ; B_{1}=B_{2}=0.425 \mathrm{pu} \mathrm{MW} / \mathrm{Hz} ; P_{R}=2000 \mathrm{MW}$ (rating), $P_{L}=$ $1740 \mathrm{MW}$ (nominal loading); $R_{1}=R_{2}=R_{3}=2.4 \mathrm{~Hz} / \mathrm{pu} \mathrm{MW} ; P f_{11}=p f_{21}=0.46966$; $p f_{12}=p f_{22}=0.37814 ; p f_{13}=p f_{23}=0.15220 ; T_{p s}=11.49 \mathrm{~s} ; K_{p s}=68.9655 \mathrm{~Hz} / \mathrm{pu} \mathrm{MW}$; $T_{12}=0.0433 \mathrm{pu} ; a_{12}=-1$

A.2 Thermal power system: $T_{g 1}=T_{g 2}=0.08 \mathrm{~s} ; T_{r 1}=T_{r 2}=10 \mathrm{~s} ; K_{r 1}=K_{r 2}=0.3 ; T_{t 1}=T_{t 2}=$ $0.3 \mathrm{~s} ; G R C=0.0017$ p.u.; Dead Band $=0.006$ p.u.

A.3 Hydro power system: $T_{r h 1}=T_{r h 2}=28.75 \mathrm{~s} ; T_{R 1}=T_{R 2}=5 \mathrm{~s} ; T_{g h 1}=T_{g h 2}=0.2 \mathrm{~s}$; $T_{w 1}=T_{w 2}=1 \mathrm{~s}$

A.4 Gas power system: $b 1=b 2=0.5 ; c 1=c 2=1 ; X_{1}=X_{2}=0.6 \mathrm{~s} ; Y_{1}=Y_{2}=1 \mathrm{~s}$; $T_{c r 1}=T_{c r 2}=0.03 \mathrm{~s} ; T_{f 1}=T_{f 2}=0.23 \mathrm{~s} ; T_{c d 1}=T_{c d 2}=0.2 \mathrm{~s}$

A.5 RFB: $K_{r i 1}=K_{r i 2}=1 ; T_{r i 1}=T_{r i 2}=0.78 ; T_{d i 1}=T_{d i 2}=0$; Gain of the Redox flow battery $=K_{r f b}=1.8$

A.6 SSSC: $T_{1}=0.2587 \mathrm{~s} ; T_{2}=0.2481 \mathrm{~s} ; T_{3}=0.2333 \mathrm{~s} ; T_{4}=0.060 \mathrm{~s} ; T_{\text {sssc }}=0.03 \mathrm{~s}$; $K_{\text {sss }}=0.2035$

\section{References}

[1] H. Bevrani, Robust Power System Frequency Control, New York: Springer, (2009).

[2] H. Shayanfar, H. A.Shayeghi and A. Jalili, "Load frequency control strategies: A state-of-the-art survey for the researcher", Energy Conversion and management, vol. 50, no. 2 (2009), pp. 344-353.

[3] K. K. Challa and Nagendra P. S. Rao, "Analysis and design of controller for two area thermal-hydro-gas AGC system", In Joint International Conference on Power Electronics, Drives and Energy Systems (PEDES), (2010), December 20.

[4] L. C. Saikia, J. Nanda and S. Mishra, "Performance comparison of several classical controllers in AGC for multi-area interconnected thermal system", International Journal of Electrical Power \& Energy Systems, vol. 33, no. 3 (2011), pp. 394-401.

[5] S. Debbarma, L. C. Saikia and N. Sinha, "Robust two-degree-of-freedom controller for automatic generation control of multi-area system", International Journal of Electrical Power \& Energy Systems, vol. 63, (2014), pp. 878-886.

[6] K. P. S. Parmar, S. Majhi and D. P. Kothari, "Improvement of dynamic performance of LFC of the two area power system: an analysis using MATLAB", International Journal of Computer Application, vol. 40, no. 10, (2012), pp. 28-32.

[7] B. Mohanty, S. Panda and P. K. Hota, "Controller parameters tuning of differential evolution algorithm and its application to load frequency control of multi-source power system", International Journal of Electrical Power \& Energy Systems, vol. 54, (2014), pp. 77-85.

[8] A. K. Barisal, "Comparative performance analysis of teaching learning based optimization for automatic load frequency control of multi-source power systems", International Journal of Electrical Power \& Energy Systems, vol. 66, (2015), pp. 67-77.

[9] S. Banerjee, J. K. Chatterjee and S. C. Tripathy, "Application of magnetic energy storage unit as loadfrequency stabilizer", IEEE Transactions on Energy Conversion, 5, no. 1, (1990), pp. 46-51.

[10] R. J. Abraham, D. Das and A. Patra, "Automatic generation control of an interconnected hydrothermal power system considering superconducting magnetic energy storage", International Journal of Electrical Power \& Energy Systems, vol. 29, no. 8, (2007), pp. 571-579.

[11] S. C. Tripathy, R. Balasubramanian and P. S. Chandramohanan Nair, "Small rating capacitive energy storage for dynamic performance improvement of automatic generation control", In Generation, Transmission and Distribution, IEE Proceedings C, vol. 138, no. 1, (1991), pp. 103-111.

[12] K. P. S. Parmar, "Load frequency control of multi-source power system with redox flow batteries: an analysis", International Journal of Computer Applications, vol. 88, no. 8, (2014), pp. 46-52.

[13] N. G. Hingorani, and L. Gyugyi, Understanding FACTS: concepts and technology of FACTS, New York: IEEE Press, (2000). 
[14] R. J. Abraham, D. Das and A. Patra, "Effect of TCPS on oscillations in tie-power and area frequencies in an interconnected hydrothermal power system", IET Generation, Transmission \& Distribution, vol. 1, no. 4, (2007), pp. 632-639.

[15] K. P. S. Parmar, S. Majhi and D. P. Kothari, "LFC of an interconnected power system with thyristor controlled phase shifter in the tie line", International Journal of Computer Applications, vol. 41, no. 9 (2012).

[16] K. Zare, M. T. Hagh and J. Morsali, "Effective oscillation damping of an interconnected multi-source power system with automatic generation control and TCSC", International Journal of Electrical Power \& Energy Systems, vol. 65, (2015), pp. 220-230.

[17] M. Ponnusamy, B. Banakara, S. S. Dash and M. Veerasamy, "Design of integral controller for Load Frequency Control of Static Synchronous Series Compensator and Capacitive Energy Source based multi area system consisting of diverse sources of generation employing Imperialistic Competition Algorithm", International Journal of Electrical Power \& Energy Systems, vol. 73 (2015), pp. 863-871.

[18] Ravi Shankar, Ravi Bhushan and Kalyan Chatterjee, "Small-signal stability analysis for two-area interconnected power system with load frequency controller in coordination with FACTS and energy storage device", Ain Shams Engineering Journal, vol. 7, no. 2, (2016), pp. 603-612.

[19] P. C. Pradhan, R. K. Sahu and S. Panda, "Firefly algorithm optimized fuzzy PID controller for AGC of multi-area multi-source power systems with UPFC and SMES", International Journal Engineering Science and Technology, vol. 19, no. 1, (2016), pp. 338-354.

[20] Praghnesh Bhatt, Ranjit Roy and S. P. Ghoshal, "Comparative performance evaluation of SMES-SMES, TCPS-SMES and SSSC-SMES controllers in automatic generation control for a two-area hydro-hydro system", International Journal of Electrical Power \& Energy Systems, vol. 33, no. 10, (2011), pp. 15851597.

[21] D. K. Lal and A.K. Barisal, "Comparative performances evaluation of FACTS devices on AGC with diverse sources of energy generation and SMES", Cogent Engineering, vol. 4, (2017), 1318466.

[22] E. Yeşil, M. Güzelkaya and I. Eksin, "Self tuning fuzzy PID type load and frequency controller", Energy Conversion and Management, vol. 45, no. 3, (2004), 377-390.

[23] B. K. Sahu, S. Pati and S. Panda, "Hybrid differential evolution particle swarm optimisation optimised fuzzy proportional-integral derivative controller for automatic generation control of interconnected power system", IET Generation, Transmission \& Distribution, vol. 8, no. 11, (2014), pp. 1789-1800.

[24] R. Storn and K. Price, "Differential evolution - a simple and efficient heuristic for global optimization over continuous spaces", J. Global Optimization, vol. 11, (1997), pp. 341-359.

[25] Kennedy, J., Eberhart, R., "Particle swarm optimization”, in: Proc. IEEE Int. Conf. Neural Networks, Perth, Australia, vol. IV, (1995), pp. 1942-1948.

\section{Authors}

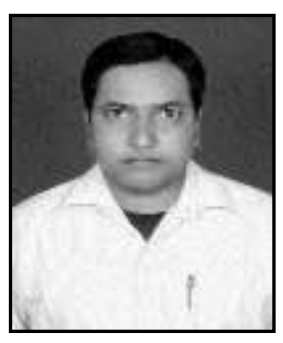

Deepak Kumar Lal born in 1984 and received the B.Tech. Degree from the BPUT, Rourkela, Odisha, in 2008 and M. Tech. degree in power system engineering in Electrical Engineering Department, National Institute of Technology, Jamshedpur, India in 2010. Since 2011, he is working as Assistant professor in the Department of Electrical Engineering, Veer Surendra Sai University of Technology, Burla, Odisha, India. His research interests include automatic generation control, economic load dispatch, renewable energy integration and power quality.

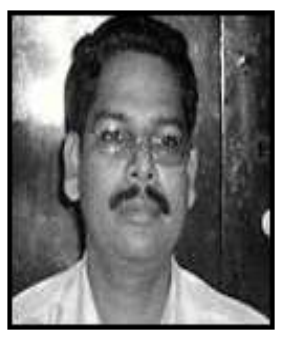

Dr. Ajit Kumar Barisal is an Associate Professor in the Department of Electrical Engineering, Veer Surendra Sai University of Technology, Burla, Odisha, India since 2006. He received the "Odisha Young Scientist award- 2010", IEI Young Engineers award- 2010" and "Union Ministry of Power, Department of power prize- 2010" for his outstanding contribution to Engineering and Technology research. His research interests include economic load dispatch, Hydrothermal Scheduling and soft computing applications to power system. 


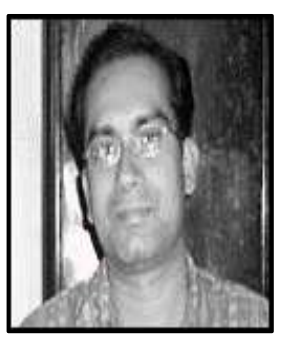

Dr. Manish Tripathy received the B.E. degree from National Institute of Technology, Rourkela, India, in 1991, and worked in Industry for five years before completing M.E. from Veer Surendra Sai University of Technology, Burla in the year 2001. He completed Ph.D. from Indian Institute of Technology, Delhi, India in the year 2009. Since 2006, he has been with the Electrical Engineering Department, Veer Surendra Sai University of Technology, Burla, Odisha, where he is an Associate Professor. His field of interest is application of intelligent techniques to power system operation and control and wind energy conversion systems. 
International Journal of Control and Automation

Vol. 11, No. 7 (2018) 